\title{
A Critical Evaluation of Qualitative Reports and Their Contributions to Educational Research
}

\author{
Mukhlash Abrar* \\ Jambi University, Jl. Lintas Jambi - Muara Bulian Km. 15, Mendalo Darat, Jambi Luar Kota, Kota Jambi, Jambi 36122
}

A B S T R A C T

\begin{abstract}
This purpose of this article was to critically assert the contribution of qualitative research in education. The article offers a theoretical exploration of qualitative (qualitative historical background, features, methods and qualitative strengths and weaknesses) and a structural critical analysis on qualitative studies (study purpose, literature review, study design, method, results and discussion, and conclusion). Two qualitative education research paper were selected and analysed with a view to arguing that qualitative research gives more contributions than others. The results of the analysis indicated that qualitative research positively contributes to education research in many ways, including the possibility of direct interaction in gathering the data, and providing in-depth and critical interpretation of meanings.
\end{abstract}

A R T I C L E I N F O

Paper type:
Empirical Research
Article history:
Received: 7 October 201
Revised: 1 November 20
Accepted: 27 November
Keywords:
- Qualitative Research
- Education Research
- Critical Evaluation

\section{Introduction}

Qualitative research is generally known as a major research methodology which focuses on the explanation, decipherment, and interpretation of people's behaviour, feelings, perspectives, or life experiences. Over the last few decades, the interest in employing this methodology has grown considerably. The growing interest in qualitative occurs due to "pluralization of life worlds" which is particularly interrelated to the study of social relation and requires the empirical study of the issue (Flick, 2014). Additionally, the application of the qualitative methodology in social studies grows rapidly due to the belief that quantitative study neglects the respondents' perspectives and experiences (Ary et al., 2013). Qualitative research is regarded as an increasingly useful method to use in various disciplines, such as psychology, health, business and management, sport, nursing, sociology, art and humanities, and education (Holloway \& Wheeler, 2013; Myers, 2013; Willig, 2008; Atkinson, 2012; Sherman \& Webb, 2004; Camic et al., 2003; Bruce \& Berg, 2001; Bogdan \& Biklen, 1997).

This paper studies critically two qualitative research reports which will cover (i) their research methodology and (ii) their contribution to study of education. In this paper, there are three main parts. Firstly, an overview on qualitative research will be presented, consisting its brief history (including its underlying theory), definition, essential features, methods, and strengths and weaknesses. Secondly, I will critically analyse chosen qualitative reports by adapting checklist of criteria for evaluating qualitative studies developed by Bromley et al. (2002) as the guideline. According to Bromley et al. (2002), assessment criteria for qualitative should ideally be applied to the entire research cycles, including study objective, literature review, study design, methods, results and interpretations, conclusion and implication. Finally, the paper will explore research contributions made by chosen journals in the field of education.

\footnotetext{
${ }^{*}$ Corresponding Author. A student at Queens' University Belfast, UK.

E-mail Address: mukhlash.abrar@unja.ac.id
} 


\section{Qualitative Research}

\subsection{Qualitative Historical Background}

Historically, qualitative research was friction on the natural model of science. It initially started from the continuous conflict and tension between two major paradigms in research world. These two paradigms refer to positivist and interpretivist perspectives (Bryman, 2001). In general, positivism is a natural-science-based approach in which objectivity and neutrality are its bases (Thompson, 1995). Within this paradigm, positivistic researchers believe that social world has a concrete and absolute reality and truth, and can be determined objectively. Interpretivists, on the other hand, argue that reality is socially constructed by human beings, and possibly be subjectively measured (Kroeze, 2012; Marcon \& Gopal, 2005; Husserl, 1965). This paradigm highlights the importance of mirroring the human being distinctions in the methods of investigation and there is no such absolute reality or truth because it may occasionally change.

Some scholars believed that there is a significant link between interpretivist paradigm and qualitative research although some partially seemed not to agree with the idea. According to Holloway \& Wheeler (2013), interpretive approach is the root of qualitative research methodology as it focuses on social reality and lived experience of human life. Similarly Mason (1996) outlines "Qualitative research is normally associated with the interpretivist sociological intellectual tradition". Furthermore, Crofts et al. (2011) ascertain that interpretivist is the paradigm of qualitative. These viewpoints support the idea that interpretivism and qualitative research are closely interrelated. However, Lapan et al. (2012) points out that qualitative researchers may employ either interpretivist or critical perspectives in their studies. Likewise, Myers as cited in Ritchie et al. (2013) states that the researchers' basic philosophical assumption, in qualitative research, underlies the notion of the study to be more interpretive or not. These contrasting views indicate the scholars' disagreement to call interpretivist as the root of qualitative research, but for some reason, the views are likely vague since they have still partly linked qualitative and interpretivism.

Despite the slight different idea on their ties, qualitative research and interpretivist paradigm are obviously linked to each other. It would appear that the underlying reason is that subjective meaning becomes the common view of both qualitative and interpretivist approaches (Flick, 2014; Bryman, 2012; Kroeze, 2012). Additionally, interpretivist school of thoughts - e.g. ethnography, phenome (nology, case study, and grounded theory - include to qualitative research strategies (Randles, 2012; Creswell, 2009). These suggest that interpretivist paradigm underpins the emersion of qualitative.

\subsection{Qualitative Definition}

"Qualitative research" is a topic frequently heard in research classes and is a never-ending issue to discuss. To date, there is no an absolute clear definition about the term because it is a challenging term to define. According to Denzin \& Lincoln (2011):

Qualitative research is difficult to define clearly. It has no theory or paradigm that is distinctively its own ... Nor does qualitative research have a distinct set of methods or practices that are entirely its own (p.6).

Due to a broad scope and the absence of its own peculiar theory, paradigm, and set of methods, it is quite difficult to provide a clear definition on qualitative research. In addition, Ritchie et al. (2013) mention that the robustness in defining qualitative research comes from its wide range of approaches as well as methods encountered in multi-research disciplines. Nevertheless, some scholars have defined the term in spite of its conflicting inherent qualities from different point of views, such as methods and approaches, data analysis, and subjectivity.

The definition of qualitative given by Denzin \& Lincoln (1994), for example, highlight on qualitative methods and approaches. They state, "Qualitative research is multi-method in focus, involving an interpretive, naturalistic approach to its subject matter" (p.2). Similarly, Clisett (2008) asserts that qualitative research covers a wide range of approaches for the exploration of "human experience, perceptions, motivations and behaviours". Moreover, Marshall \& Rossman (1999) define, "Qualitative research is pragmatic, interpretive, and grounded in the lived experiences of people" (p.2). These suggest that qualitative research encompasses a vast array of 
methods and approaches within the various disciplines. Different views of qualitative research, in terms of its analysis, was given by Strauss \& Corbin (1998). They claim "By the term qualitative research we mean any kind of research that produces findings not arrived at by means of statistical procedures or other means of quantification" (p.17). Likewise, Punch (2005) emphasises, "Qualitative research is empirical research where the data are not in the forms of numbers" (p.3). Their views on qualitative positioning obviously indicates that it is a non-numerical based or non-statistical research. Then, Flick (2014) defines qualitative from its subjectivity. He posits, "Qualitative research is oriented towards analysing concrete cases in their temporal and local particularly and starting from people's expression and activities in their local context" (p. 21). His viewpoint denotes that the qualitative result cannot be generalised and might change periodically.

The above scholars' views seem dissimilar because they used distinct research angles in determining what qualitative research is. However, there is a common thread among the views which signifies that qualitative research concerns with the way human beings make sense of, or interpret, their experiences and world because qualitative research has an important role to play in understanding in this world and in completing other forms of knowledge (Darlington \& Scott, 2002).

\subsection{Qualitative Features}

The following characteristics clarify further its meaning and its clear cut differences from quantitative research. There are, at least, seven characteristics summarised from a number of references in the literature which distinguish it from quantitative work (Flick, 2014; Holloway \& Wheeler, 2013; Holloway \& Brown, 2012; Creswell, 2009; Willig, 2008; Hancock, 1998; Strauss \& Corbin, 1998; Kottak, 2006; Walsh \& Wigens, 2003; Harris, 1976; Geertz, 1973). Firstly, the distinctive key feature of qualitative research is 'primacy data' (Holloway \& Brown, 2012). This means the data of empirical studies plays a pivotal role as the start of inquiry. Then, the collected data from single examples, cases, or instances generate a more generic principle better known as a 'theory'. Similarly, Holloway \& Wheeler (2013) point out that qualitative research prioritises data as they either create a novel theoretical theory or support the existing idea; in other words, a theoretical framework or hypothesis is not pre-determined in qualitative work because it is authentically an inductive process. The process is evident to several types of qualitative traditions, especially Grounded Theory (Corbin $\&$ Strauss, 1990). However, that is not to say that qualitative researchers never employ deductive approach in their works because some researchers sometimes use deductive reasoning when collecting additional data (Holloway \& Brown, 2012).

Secondly, qualitative study is 'contextualisation'. Regarding this, Holloway \& Brown (2012) and Flick (2014) assert that qualitative work is context-bound, temporal, and local in nature. This shows that qualitative researchers cannot make sense of data in isolation from context as they are socially and culturally bounded. This shows that every aspect in qualitative research is context-specific, including research data, participants, and researchers themselves. As a result, the findings of the study may be dissimilar to one another and cannot be generalised. Additionally, Willig (2008) argues that qualitative work is concerned with the meaning through context and aims at grasping a particular context.

Thirdly, qualitative researchers entirely immerse themselves in participants' natural settings. 'Natural setting' means a researcher submerging themselves where subjects' practices and interaction in everyday context, not in artificial circumstances, such as in a laboratory or controlled experiments Flick (2014) takes places. The qualitative researchers, in the process of data collection, tend to be natural by not setting up the research environment. In some cases, they get involved in the participants' real life, as in ethnography study. Thus, qualitative has the 'naturalistic' quality. According to Walsh \& Wigens (2003), the tendency of naturalistic researchers is paying attention at specific group of people or a particular situation in a real context, not to locate the absolute 'truth' or build causal relationship.

Fourthly, qualitative research focuses on the emic perspective or insider's perspective, (Holloway \& Brown, 2012). This perspective pertains to exploring peoples thoughts Kottak (2006) from the perspectives of the people involved in the research. Furthermore, Lett (1990) explains, "Emic constructs are accounts, descriptions, and analyses expressed in terms of the conceptual schemes and categories regarded as meaningful and appropriate by the native members of the culture whose beliefs and behaviours are being studied" (p.130). These suggest that the researchers needs to put aside all prior assumptions and allow the participants to speak. This is certainly helpful to gain more understanding on participants' diversity, including their cultures and settings. Furthermore, Harris (1976) says that interaction - asking people's feelings and thoughts - is one of the ways to understand people and get into their perspective. 
Fifthly, qualitative research yields a 'thick' description (Geertz, 1973), which covers in-depth and detailed descriptions of participants' behaviours, feelings, opinions, processes, actions, and experiences. A good 'thick' description has to be theoretical and analytical, Holloway \& Brown (2012) which means that the researchers does not only report the raw findings, but they also analyse and interpret them by providing relevant supporting data on the issue. In addition, resulting a 'thick' description also depends on the way the data will be collected. Qualitative research traditions investigates the answers of the question initiating with: why? How? In which way? Hancock (1998) by employing various methods, including observations, interviews, documents, and audio-visual materials (Creswell, 2009). Those question types and methods explore rich data from the respondents and possibly result a 'thick' interpretation on the phenomenon.

Sixthly, qualitative research enables 'close researcher-participant relationships' particularly in qualitative field research. As it is a well-known fact that most qualitative research strategies, e. g. phenomenology and case studies, involve other people, a positive rapport based on a position of equality as human beings is definitely required. It is necessary because researchers may reveal sensitive and private issues around the phenomena. As an illustration, the study undertaken by Morrissey \& Higgs (2006) successfully explored a sensitive issue in their interview, specifically what females' first sexual intercourse experience was.

The last distinctive feature of qualitative research relates to the inquiry report representation that is 'narrative'. According to Holloway \& Biley (2011), "Tension and interest in outcomes are essential traits for qualitative inquiry; they make the story readable and its content communicable. Communication of the finding is, after all, the aim of all research" (p. 970). This clearly represents that qualitative reports are dominant in words, phrases, clauses, and sentences, but not in numbers. It also implies that qualitative results are nonstatistical and non-quantifiable (Strauss \& Corbin, 1998).

Although the above features show qualitative research's apparent distinction from quantitative, they do have similarities. One vivid similarity is that both research methodologies attempt to examine or investigate the 'truth' of existing phenomena.

\subsection{Qualitative Methods}

Method, in the world of research, is generally defined as a way to collect or gain the data. In qualitative, there are a wide variety of methods that are commonly employed by the researchers, including observations, interviews, focus groups, and audio-visual materials (Creswell, 2009; Dörnyei, 2007; Marshall \& Rossman, 1999; Krueger \& Casey 2000). These methods are different in nature and have distinctive strengths and limitations.

The first qualitative method is observation. In this method, the researcher takes field note or checklist on participants' behaviour and activities at the research site. The observer may engage in various roles, including complete participant, observer as participant, participant as observer, and complete observer (Creswell, 2009) depending on the design of research. This method is frequently used for ethnography studies which aims to observe social interactions and behaviours that occur within groups, organisations, and also communities. Observation is useful to explore the topics that may be uncomfortable for respondents to talk about, and to observe their behaviours in natural settings. However, the researchers, who cannot adjust the environment well, may be seen as intrusive. In addition, not all observable information, particularly sensitive and private issues, can be reported.

Secondly, a very common qualitative method which intends to elicit participants' views and opinions is indepth interview (Creswell, 2009; Marshall \& Rossman, 1999). The interviewer possibly conducts this method in many different formats, such as face-to-face interviews, or online interviews via telephone, and online applications with structured, semi-structured, or unstructured interview design. This method is appropriate for participants who cannot be directly observed. It also allows the researchers to gain in-depth interview data, including participants' historical information. Although an interview has potential to obtain rich data from participants, the issues on bias and unnatural setting seem to be its limitations.

The third qualitative method is focus groups. This method, in a way, resembles interviews, but the format and the interviewer's role are considerably very different. According to Dörnyei (2007), collective experience of group brainstorming is the basis of focus groups format. In this sense, this method involves a group format which normally consists of 6-10 participants and they actively respond to the emerging issues and points. Additionally, Krueger \& Casey (2000) outlines that the interviewer's role is to create a nurturing environment that encourages different perceptions from the participants about particular issues, without pressuring them to vote, plan or reach consensus. It is clear that the researcher acts as a moderator and plays a significant role in 
the success of focus groups. This method is certainly fruitful to obtain detailed information about personal and group feelings, experiences, and perspectives in an economical way because the researcher interviews more than one respondent at a time. This method is also perceived as a high face validity method as it takes the advantage of the people naturally interact in a group and are influenced by the others. Nevertheless, there may some chaos in data collection and interpretation processes.

The next method is audio-visual materials. The data for this method may take from various sources, such as photographs, video-tapes, art-objects, computer and electronic messages, any forms of sounds, and films (Creswell, 2009). This method has historically been used in anthropology study, such as Franz Boas, Bronislaw Malinowski, and Young. It is believed that the use of audio-visual materials method during the research provides an opportunity for the participants to directly share their reality. Furthermore, this method is seen as creative since it can capture attention visually. However, the presence of the researcher to take photographs or videos may be disruptive and affects the participants' responses and attitudes.

In many qualitative studies, the researchers use multiple data collection methods (triangulation) as it is perceived that the use of a single method can never adequately shed light on a phenomenon. Qualitative researchers use triangulation techniques as an attempt to ensure an account is rich, deep, robust, and also welldeveloped. More importantly, this technique strengthens the reliability and validity of the data (Creswell, 2009; Merriam, 1998).

\subsection{Qualitative Strengths and Weaknesses}

Qualitative research, similar to other research disciplines has its strengths and weaknesses. One of the obvious merits is that this methodology can capture, explore, and understand the particular phenomena occurred in community or embedded in local contexts. Since qualitative positioning ascribes to social or human issues (Creswell, 2009) in the level of individuals, groups, or organisations, it focuses specifically on research problems rather than sensitive concepts. It also provides comprehensive details about human behaviours, feelings, life experiences, opinions, actions, as well as emotions that other inquiries, quantitative, cannot match. Secondly, in terms of data, qualitative research possibly gains rich data from the participants and results indepth interpretations due to its multiple methods and approaches which can be employed both in collecting data via observations, interviews, documents, photo voice, or by analysing the data through content analysis, within case and cross-case displays and analysis, thematic analysis (Creswell, 2009; Blaxter et al., 2006; Mason, 1996; Miles \& Huberman, 1994). The data obtained from a number of evidences, then, becomes the 'ground' or new knowledge concept (Yin, 2010). In other words, qualitative findings may develop 'theory' or support the existing view as the nature of inquiry is inductive.

Despite the above strengths, qualitative research has been criticised for numerous reasons. The most apparent issue circling qualitative research is its subjectivity. Subjectivity in qualitative inquiry is an issue that has been discussed and debated for years. It arises because the researcher is part of research process itself. $\mathrm{He} / \mathrm{she}$ is the one who decides what to focus in his/her study, and it potentially influences the research findings (Thomson, 2011). Hence, the results are regarded as bias. Another critique on the nature of qualitative is 'size of sample'. It is a well-known fact that qualitative relatively involves small participants/ respondents and it occasionally does not represent the samples of all cases. In relation to this issue, Harry \& Lipsky (2014) state that research validity is normally queried because of smaller samples. Additionally, Thomson (2011); Flick (2014) claim that a small number of respondents leads to the problem in generalising the finding.

\section{Critical Article Reviews}

As an attempt to critically examine whether the research report is well carried out in line with the paradigm of qualitative methodology and assess whether the contribution made is significant, two articles in relation to education field of study have been selected and reviewed in this paper. The underlying reason of choosing the articles is because both were published in peer-reviewed journals. In addition to that, both articles shared related topics. A thorough analysis by adapting Bromley et al. (2002) checklists of criteria for evaluating qualitative research was used. The analysis comprises six important parts in qualitative research, including study purpose, literature review, study design, methods, finding, and discussion. 
Article 1: Mukminin, A., \& McMahon, B. J. (2013). 'International Graduate Students' Cross-Cultural Academic Engagement: Stories of Indonesian Doctoral Students on an American Campus'. The Qualitative Report, 18(35), $1-19$.

Article 2: Novera, I. A. (2004). 'Indonesian Postgraduate Students Studying in Australia: An Examination of Their Academic, Social and Cultural Experiences'. International Education Journal, 5(4), 475-487.

\subsection{Study Purpose}

In terms of study purpose, both articles clearly stated the aim of study in the abstracts and introduction sections. Article one, for instance, attempted to "explore the lived experience of academic engagement of twelve Indonesian doctoral students attending an American graduate school during their first term and over time in their institutions" (Mukminin, \& McMahon, 2013). To be more specific, this study focused on the engagement at the classroom level and on how the participants negotiated their cultural values in their cultural encounters in an American graduate school. The main aim of the article two is "investigate the adjustment experiences of 25 Indonesian postgraduate students (8 female, 17 male) studying in universities in Victoria" (Novera, 2004). In his study, the focus was on three adjustment experience issues, most notably academic, social, and cultural experiences. These purposes of both articles indicate that a qualitative methodology is appropriate to be used since it interprets, and makes sense of human beings' experiences, behaviour, feelings, perspectives, facts, and opinions.

\subsection{Literature Review}

A review of the literature is an essential part in the research paper. This section is designed to provide an overview of sources the researcher(s) have explored regarding to the topic of interest, and to demonstrate to readers how the study fits within the larger scope of study (Ridley, 2012; Hart, 1998). It contains information on background of the study, research gaps, and previous studies. The author of both articles explicitly explained the gaps in current knowledge and studies about the topic of interest, and justified the need for the study being reported. They also, with different writing styles, seemed to include relevant literature reviews as the basis of their study. In the article one, the authors specifically provided a section on theoretical framework which concisely contains pertinent theories and studies to the chosen topic. The author of the article two, in contrast, presented his literature review part by breaking it down into some specific and detailed explanations. However, there was a lack of information under the heading of 'Islam' in his article, and the additional arguments may be needed.

\subsection{Study Design}

Both articles appeared to have the same study design, which is qualitative. Regarding this issue, the authors of the first article explicitly stated that they used qualitative design with phenomenological approach in their study. In contrast to the article one, there was no any explicit information on the research design in article two, so the readers may find it difficult to identify it at the beginning. The clear explanation on research design is substantially needed because it helps the readers understand the nature of study. I, as the reviewer, assume that the author of the article two employed the same research design as the article one from its aim of the study. Phenomenology is appropriate for the research question and objectives of both articles (See Study Purpose) as they tried to explore participants' lived experience of the phenomena. Creswell (2007), Streubert \& Carpenter (2002), Merriam (1998), and Patton (1990) note that the essence of phenomenological study is to understand and explore how individual(s) experiences a phenomenon from their personal words and perspectives.

\subsection{Methods}

In general, research methods section draws the rationale of specific procedures used to identify, collect, and analyse the data in the study. It also describes the techniques on how the researchers choose their samples (Kallet, 2004). This indicates that methods section answers three main questions: How was the sample chosen? How was the data generated? And how was it analysed? 
One of the problematic issues in qualitative research is the sufficient number of samples. It is perceived that qualitative samples should be large enough as an attempt to make sure that most or all of the required data are covered because each participant may have different perceptions at the same phenomenon, but at the same time if the sample is too large, the data becomes repetitive and, eventually, superfluous. Some writers distinctively suggested that what constitutes a sufficient sample size in qualitative, including in phenomenological study. Creswell (2007), for instance, recommends the sample size in a range between five to twenty-five participants. Moreover, Morse (1994) mentions that six participants is the minimum sample size for the research design. These suggest that having six to twenty-five participants as the samples is ideal in phenomenological inquiry. However, as previously noted that the emphasis of qualitative is on depth insights (Holloway \& Brown, 2012; Hancock, 1998; Denzin, 1989; Geertz, 1973) and not numbers, it is possible to have one participant in the study. Regarding the research participant issue, the authors of both articles seem to have enough sample for their research (twelve total participants in the article one, and twenty-five respondents in the article two).

Another issue in qualitative research is the research instrument. It relates to the way the researchers gather their data. The appropriate data collection method does help them gain rich data from the participants. In relation to this, both articles did elaborate the methods used to generate the data in the study. The authors of article one have developed the most common qualitative data collection technique, which is a semi-structured in-depth interviews. This method certainly accommodates them to explore in-depth data because they have opportunities to further investigate, confirm, and clarify the questions, but bias in data interpretation might occur. The author of article two, on the contrary, employed an open-ended questionnaire as the main research instrument. This is a common technique used in qualitative research, but has some weaknesses. One obvious limitation is that the researcher may not be able to deeply examine the phenomenon as s(he) only relies on the respondents' written answers. Both articles' authors used qualitative data collection methods, and, for some reason, are appropriate for the research objectives. However, the use of triangulation by methods (interview, observation, and focus group) may be helpful to get richer, deeper, more robust, and also more well-developed data and to strengthen their validity and reliability (Creswell, 2009; Merriam, 1998).

Regarding the data analysis technique, there was a comprehensive explanation on how the researchers analysed the data in article one. They did inductive analysis by using (Miles \& Huberman, 1994) within-case and cross-case displays and analysis as a guide to generate the themes and sub-themes from the data. They clearly described data analysis steps from the beginning and explicitly reported trustworthiness issue. To ensure their interpretation, the researchers did triangulation by researchers (more than one researcher to analyse, and develop the coding scheme) and by theories (multiple theories and perspectives' consideration during the process of data analysis and interpretation). The author of article two, unfortunately, did not include any detailed information on trustworthiness and on how the themes and subthemes were emerged. A more elaborate explanation on these matters may necessarily be added to give a complete portrayal of his study.

\subsection{Results and Discussions}

In a research article, result and discussion sections are crucial parts because they both contain information and interpretation regarding research problems. The Results section is where the author(s) reports and states the findings of the study based on the applied methodologies in gathering the information, and arranges them in a logical order. Whereas, discussion section contains the interpretation and description of findings' significance in relation to the research problems being investigated. It, ideally, also explains new or fresh insights about the problems, presents underlying meaning of research, notes possible implications to other areas of study, and explores potential improvements that can be done in order to further develop the concerns of the research (Annesley, 2010; Burton et al., 2008; Bitchener \& Basturkmen, 2006; Brett, 1994).

Both articles, with different writing system, comprehensively presented research findings and interpretations' description. In article one, the authors wrote the two sections separately. In finding section, they elucidated their interview results completed with some interview quotations in a well-organised structure by presenting them in appropriate themes and sub-themes, while in the discussion, they interpreted the results critically and correlated them with the topic-related studies and theories. The author of the article two, conversely, elaborated all information under the heading 'the study finding and discussion'. He provided detailed results of his open-ended questionnaire as well as his results' critical interpretations in a very logical order. Overall, it can be said that both articles demonstrated a well-developed report. 


\subsection{Conclusion}

A conclusion contains a synthesis of key research points and, if applicable, it provides suggestions or recommendations for future researchers or research topics. In article one, there was not a section on conclusion heading, but the authors concluded their study in limitation and implication sections. They in particular pointed out their key research points, research limitations, and recommendations to policy makers, and further researchers. Article two consisted a specific section on conclusion. The writer, here, comprehensively summarized the discussion and made some suggestions to develop the concerns of research, including to other researchers, academics, and university staffs. These suggest that both articles' conclusions seemed to have good writing representation and be consistent as well as congruent with the reported findings.

\section{The Value of Qualitative Methods in Education Research}

Despite their strengths and weaknesses, it can be argued that both articles are qualitative in nature. They also showed that qualitative research is deemed appropriate and contributive to investigate phenomenon associated with education field of study. There are, at least, two underlying reasons why this claim can be made. First, qualitative research allows the education researchers to gain in-depth, rich, and robust data on the phenomenon of interest because they get the opportunity to have a direct interaction with the participants. Mukminin and McMahon, for instance, elicited their participants' views through a semi-structured in-depth interview (article one). The use of this data collection tool helped them explore the problems in detail, so they can come up with specific themes and sub-themes and well-organised findings. Second, Qualitative inquiry enables the researchers to present comprehensive explanation and interpretation as it concerns with 'thick' description (Holloway \& Brown, 2012; Hancock, 1998; Denzin, 1989; Geertz, 1973). In both chosen articles, the authors not only presented raw findings of data, but also critically interpreted their participants' experiences, perspectives, feelings, and opinions on academic, social, and cultural engagements studying in the USA and Australian universities and correlated them with the existing theories and previous studies to fill the gaps in current related knowledge and research. Their discussions were even deeper as they ended up with research implications and suggestions. In addition, education researchers across the world are increasingly employing qualitative research in their study as an attempt to deeply investigate the phenomena existing in education. Some of them are Akasha (2013), Wright \& Schartner (2013), Nguyen (2011) and Lee (2009). These indicate that qualitative research methods play a useful role in education research.

\section{Conclusion}

The purpose of this study was to verify the value of qualitative research methods in education research through critically analysing the qualitative articles. The findings suggest that qualitative inquiry positively contributes to education research in many ways, including the possibility of direct interaction in gathering the data, and providing in-depth and critical interpretation of meanings. However, this is not to say that this study has no limitations. One of which is that the discussion only focused on general qualitative methods, without specifying any particular qualitative approaches. Therefore, this essay has thrown up these issues in need of further investigation.

\section{References}

Akasha, O. (2013). Exploring the Challenges Facing Arabic-Speaking ESL Students \& Teachers in Middle School. Journal of ELT and Applied Linguistics (JELTAL), 1(1), 12-31.

Annesley, T. M. (2010). The discussion section: Your closing argument. Clinical chemistry, 56(11), 16711674.

Ary, D., Jacobs, L., Sorensen, C. and Walker, D. (2013). Introduction to research in education. Cengage Learning

Atkinson, M. (2012). Qualitative research on sport and physical culture (Vol. 6). Emerald Group Publishing.

Bitchener, J., \& Basturkmen, H. (2006). Perceptions of the difficulties of postgraduate L2 thesis students writing the discussion section. Journal of English for Academic Purposes, 5(1), 4-18.

Blaxter, L., Hughes, C., \& Tight, M. (2006). How to research. Milton Keynes: Open University Press. 
Bogdan, R., \& Biklen, S. K. (1997). Qualitative research for education. London: Allyn \& Bacon.

Brett, P. (1994). A genre analysis of the results section of sociology articles. English for Specific Purposes, 13(1), 47-59.

Bromley, H., Dockery, G., Fenton, C., Nhlema, B., Smith, H., Tolhurst, R. and Theobald, S., (2002). Criteria for evaluating qualitative studies. Liverpool: Liverpool School of Tropical Medicine.

Bruce, B., \& Berg, M. (2001). Qualitative research methods for the social sciences. London: Ally and Bacon. Bryman, A. (2001). Social Research Methods. Oxford: Oxford University Press.

Bryman, A. (2012). Social Research Methods, $4^{\text {th }}$ ed. Oxford: Oxford University Press.

Burton, N., Brundrett, M., \& Jones, M. (2008). Doing your education research project. CA: Sage.

Camic, P. M., Rhodes, J. E., \& Yardley, L. E. (2003). Qualitative research in psychology: Expanding perspectives in methodology and design. American Psychological Association.

Clisett, P. (2008). "Evaluating Qualitative Research", Journal of Orthopedic Nursing, 12, 99-105.

Corbin, J. M., \& Strauss, A. (1990). Grounded theory research: Procedures, canons, and evaluative criteria. Qualitative Sociology, 13(1), 3-21.

Creswell, J. W. (2007). Qualitative enquiry and research design: Choosing among five approaches. Thousand Oaks, CA: Sage.

Creswell, J. W. (2009). Research design: Qualitative, quantitative, and mixed methods approaches. Thousand Oaks, CA: Sage publications.

Crofts, J., Hungria, S., Monfries, J. and Wood, M. (2011). Theoretical paradigms: positivism, feminism and interpretivism. Available at: http://dbdaishu.com/blog/?p=238/ (Accessed: 2 February 2014).

Darlington, Y. and Scott, D. (2002). Qualitative research in practice: Stories from the Field, Buckingham: Open University Press.

Denzin, N. K. (1989). Interpretive interactionism. Newbury Park, CA: Sage.

Denzin, N.K. and Lincoln, Y.S. (1994). Handbook of qualitative research. London: Sage.

Denzin, N.K. and Lincoln, Y.S. (2011). Handbook of qualitative research, $4^{\text {th }}$ ed. London: Sage.

Dörnyei, Z. (2007). Research methods in applied linguistics: Quantitative, qualitative, and mixed methodologies. Oxford: Oxford University Press.

Flick, U. (2014). An introduction to qualitative research, $5^{\text {th }}$ ed. London: Sage.

Geertz, C. (1973). 'Thick description: toward an interpretive theory' in Geertz, C. (ed.) The interpretation of cultures. New York: Basic Book.

Hancock, B. (1998). An introduction to Qualitative research. UK: Trent Focus Group.

Harris, M. (1976). History and significance of the emic/etic distinction. Annual Review of Anthropology, 5, 329-350.

Harry, B. and Lipsky, M. (2014). Qualitative research on special education teacher preparation. Handbook of research on special education teacher preparation, 445.

Hart, C. 1998. Doing a literature review: Releasing the social science research imagination. CA: Sage.

Holloway, I. and Biley, F.C., (2011). Being a qualitative researcher. Qualitative health research, 21(7), 968975.

Holloway, I., \& Brown, L. (2012). Essentials of a qualitative doctorate. Left Coast Press.

Holloway, I., \& Wheeler, S. (2013). Qualitative research in nursing and healthcare. John Wiley \& Sons.

Husserl, E. (1965). Phenomenology and the crisis of philosophy. New York: Harper Torchbooks.

Kallet, R. H. (2004). How to write the methods section of a research paper. Respiratory care, 49(10), 12291232.

Kottak, C. (2006). Mirror for Humanity, New York. New York: McGraw Hill.

Kroeze, J. H. (2012). 'Postmodernism, interpretivism, and formal ontologies' in Mora, M, et al. (ed.) Research Methodologies, Innovations and Philosophies in Software Systems Engineering and Information Systems. USA: Information Science Reference.

Krueger, R.A. and Casey, M.A., (2000). Focus groups. Thousand Oaks, CA: Sage.

Lapan, S. D., Quartaroli, M. T. and Riemer, F. J. (2012). Qualitative Research: An Introduction to Methods and Designs. San Francisco: Jossey-Bass.

Lee, G. 2009. Speaking up: Six Korean students' oral participation in class discussions in US graduate seminars. English for Specific Purposes, 28(3), 142-156.

Lett, J. (1990). Emics and etics: Notes on the epistemology of anthropology. Emics and etics: The insider/outsider debate, 7, 127-142

Marcon, T., \& Gopal, A. (2005). Uncertain knowledge, uncertain time. Toronto: ASAC. 
Marshall, C., \& Rossman, G. B. (1999). Designing qualitative research, Thousand Oaks, CA: Sage publications.

Mason, J. (1996). Qualitative researching. London: Sage Publication.

Merriam, S. B. (1998). Qualitative Research and Case Study Applications in Education. San Francisco, CA: Jossey-Bass.

Miles, M. B., \& Huberman, A. M. (1994). Qualitative data analysis: An expanded sourcebook. 1994. San Francisco, CA: Sage Publications.

Morrissey, G., \& Higgs, J. (2006). Phenomenological research and adolescent female sexuality: discoveries and applications. The Qualitative Report, 11(1), 161-181.

Morse, J. M. (1994). Designing funded qualitative research. In N.K Denzim \& Y.S. Lincoln (eds.), Handbook of qualitative research (pp.220 - 235). Thousand Oaks, CA: Sage Publication.

Mukminin, A., \& McMahon, B. J. (2013). International Graduate Students' Cross-Cultural Academic Engagement: Stories of Indonesian Doctoral Students on an American Campus. The Qualitative Report, 18(35), 1-19.

Myers, M. D. (2013). Qualitative research in business and management. London: Sage.

Nguyen, C. T. 2011. Challenges of learning English in Australia towards students coming from selected Southeast Asian countries: Vietnam, Thailand and Indonesia. International Education Studies, 4(1), 13.

Novera, I. A. (2004). Indonesian Postgraduate Students Studying in Australia: An Examination of Their Academic, Social and Cultural Experiences. International Education Journal, 5(4), 475-487.

Patton, M. Q. (1990). Qualitative evaluation and research methods. Thousand Oaks, CA: Sage.

Punch, K. F. (2005). Introduction to social research: Quantitative and qualitative approaches. London: Sage.

Randles, C. (2012). 'Phenomenology: A review of the literature', Update: Applications of Research in Music Education, 8755123312436988.

Ridley, D. (2012). The literature review: A step-by-step guide for students. Los Angeles, CA: Sage.

Ritchie, J., Lewis, J., Nicholls, C. M., \& Ormston, R. (Eds.). (2013. Qualitative research practice: A guide for social science students and researchers. London: Sage.

Sherman, R. R., \& Webb, R. B. (Eds.). (2004). Qualitative research in education. London: Routledge.

Strauss, A. and Corbin, J. (1998). Basics of Qualitative Research. London: Sage Publications.

Streubert, H. J., \& Carpenter, D. R. (2002). Qualitative research in nursing: Advancing the humanistic imperative, $3^{\text {rd }}$ ed. Philadelphia: Lippincott Williams \& Wilkins.

Thompson, N. (1995). Theory and practice in health and social welfare. Buckingham: Open University Press.

Thomson, S. B. (2011). 'Qualitative Research: Validity', JOAAG, 6 (1), 77-82.

Walsh, M., \& Wigens, L. (2003). Introduction to research. Cheltenham: Nelson Thornes.

Willig, C. (2008). Introducing qualitative research in psychology: Adventures in theory and method. McGraw-Hill: Open University Press.

Wright, C., \& Schartner, A. (2013). 'I can't... I won't? 'International students at the threshold of social interaction. Journal of Research in International Education, 12(2), 113-128.

Yin, R. K. (2010). Qualitative research from start to finish. London: Guilford Press. 